\title{
Proteomic study of hypothalamus in pigs exposed to heat stress
}

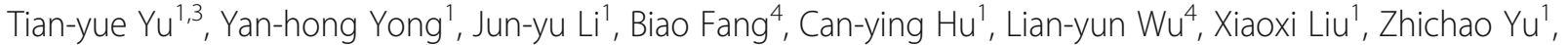 \\ Xingbin $\mathrm{Ma}^{1}$, Yadnyavalkya Patil ${ }^{2}$, Ravi Gooneratne ${ }^{2}$ and Xiang-hong Ju, ${ }^{1,3^{*}}$ (D)
}

\begin{abstract}
Background: With evidence of warming climates, it is important to understand the effects of heat stress in farm animals in order to minimize production losses. Studying the changes in the brain proteome induced by heat stress may aid in understanding how heat stress affects brain function. The hypothalamus is a critical region in the brain that controls the pituitary gland, which is responsible for the secretion of several important hormones. In this study, we examined the hypothalamic protein profile of 10 pigs ( $15 \pm 1 \mathrm{~kg}$ body weight), with five subjected to heat stress $\left(35 \pm 1{ }^{\circ} \mathrm{C}\right.$; relative humidity $\left.=90 \%\right)$ and five acting as controls $\left(28 \pm 3{ }^{\circ} \mathrm{C} ; \mathrm{RH}=90 \%\right)$.

Result: The isobaric tags for relative and absolute quantification (iTRAQ) analysis of the hypothalamus identified 1710 peptides corresponding to 360 proteins, including 295 differentially expressed proteins (DEPs), 148 of which were up-regulated and 147 down-regulated, in heat-stressed animals. The Ingenuity Pathway Analysis (IPA) software predicted 30 canonical pathways, four functional groups, and four regulatory networks of interest. The DEPs were mainly concentrated in the cytoskeleton of the pig hypothalamus during heat stress.

Conclusions: In this study, heat stress significantly increased the body temperature and reduced daily gain of body weight in pigs. Furthermore, we identified 295 differentially expressed proteins, 147 of which were down-regulated and 148 up-regulated in hypothalamus of heat stressed pigs. The IPA showed that the DEPs identified in the study are involved in cell death and survival, cellular assembly and organization, and cellular function and maintenance, in relation to neurological disease, metabolic disease, immunological disease, inflammatory disease, and inflammatory response. We hypothesize that a malfunction of the hypothalamus may destroy the host physical and immune function, resulting in decreased growth performance and immunosuppression in heat stressed pigs.
\end{abstract}

Keywords: Pigs, Heat stress, Hypothalamus, Quantitative proteomics

\section{Background}

Pigs are homeotherms with under-developed sweat glands. Therefore, at high temperature, pigs experience stress more than other species [1]. Heat stress (HS) affects pigs markedly, including changes to the metabolism of several organ systems [2], deposition of fat [3], disruption

\footnotetext{
* Correspondence: juxh77@163.com

'Department of Veterinary Medicine, Guangdong Ocean University, Zhanjiang 524088, China

${ }^{3}$ Department of Animal Science, Guangdong Ocean University, Zhanjiang 524088, China

Full list of author information is available at the end of the article
}

to energy balance [4], and lowering of meat quality [5]. Bell reported that during HS, the barrier function of the intestinal mucosa may be compromised due to increased hypoxia and formation of free radicals in pig visceral organs [6]. Ju et al. reported that HS alters immune and biochemical indexes leading to metabolic and endocrine disorders in Bama miniature pigs [7]. Now, more than ever, it is important to understand the susceptibility of livestock to stress induced diseases in relation to immune system functioning and understand the mechanism behind such diseases, because most emerging animal diseases are seriously threatening public health.

C The Author(s). 2020 Open Access This article is licensed under a Creative Commons Attribution 4.0 International License, which permits use, sharing, adaptation, distribution and reproduction in any medium or format, as long as you give appropriate credit to the original author(s) and the source, provide a link to the Creative Commons licence, and indicate if changes were made. The images or other third party material in this article are included in the article's Creative Commons licence, unless indicated otherwise in a credit line to the material. If material is not included in the article's Creative Commons licence and your intended use is not permitted by statutory regulation or exceeds the permitted use, you will need to obtain permission directly from the copyright holder. To view a copy of this licence, visit http://creativecommons.org/licenses/by/4.0/. The Creative Commons Public Domain Dedication waiver (http://creativecommons.org/publicdomain/zero/1.0/) applies to the data made available in this article, unless otherwise stated in a credit line to the data. 
The hypothalamic-pituitary-adrenal axis is the most important pathway in the physiological control of stress [8]. Its activation starts with the secretion of corticotropin-releasing hormone from the hypothalamic paraventricular nucleus; this promotes the release of adrenocorticotropic hormone from the pituitary, which in turn releases glucocorticoids from the adrenal cortex [9]. Sutherland et al. observed a decrease in levels of plasma cortisol (a major glucocorticoid) in pigs exposed to HS for 21 days [10]. Kataria detected significantly higher levels of serum prolactin and cortisol in pigs exposed to a higher temperature $\left(45^{\circ}-46^{\circ} \mathrm{C}\right)$ [11]. In cattle, cortisol increased in the early stages of HS but subsequently returned to normal levels [12]. Hence, the objective of our study was to examine the function and interaction of deferentially expressed proteins (DEPs) in the hypothalamus of pigs subjected to HS. This would provide the basis for further study of the mechanism of HS effects on the physiological function and metabolism of the hypothalamus.

Isobaric tags for relative and absolute quantification (iTRAQ) technology is a comparative proteomic science developed in recent years [13]. It has been used to describe proteomic analysis of the hypothalamic response during sleep regulation [14], feeding patterns [15], microgravity conditions [16], anesthesia [17], exposure to environmental toxicants [18], and reproductive cycles [19]. In previous studies, when the ambient temperature was maintained at $35 \pm 1{ }^{\circ} \mathrm{C}$ and the relative humidity was maintained at $90 \%$, the body temperature of pigs was shown to increase by 0.5 to $1^{\circ}$, and the respiratory rate also increased significantly [20]. In this study, we used iTRAQ technology to study proteomic changes in the hypothalamus of pigs exposed to HS for 7 days to determine the mechanism of immune regulation and to provide a theoretical basis for the control and prevention of HS.

\section{Results}

\section{Clinical changes caused by heat stress}

We measured the body weight, rectal temperature, and forehead temperature of pigs on days 1 to 7 of implementing the heat stress treatment. The body weight of pigs was significantly reduced on day 7 of heat stress (Fig. 1a). Under heat stress conditions, both forehead temperature and rectal temperature of pigs were higher than control, the most difference between heat stressed and control pigs appearing on day 7 (Fig. 1b, c). These results indicated that heat stress significantly affected the growth performance (in terms of the abovementioned traits) of pigs.

iTRAQ-based DEP identification and quantitative analysis of swine hypothalamic tissue

All protein and peptide identifications were obtained by database searching and stringent data filtering. The LCMS/MS analysis produced 7072 spectra, corresponding to 2882 unique peptides; 360 proteins were identified at a false discovery rate (FDR) of $\leq 0.01$ (Fig. 2a). According to the level of protein abundance, proteins were regarded as different proteins when the difference multiple reached 1.5 or more, and the statistical test showed significant difference $(p<0.01)$. Thus, there were 295 DEPs identified in the hypothalamus, of which 148 were up-regulated and 147 were down-regulated. As shown in Table 1, 40 key DEPs were selected, including information on 20 up-regulated proteins and 20 down-regulated proteins. The information of all the determined DEPs is shown in Supplementary Table 1.

The molecular weights of most DEPs were in the range of 20-60 kD (157 DEPs) (Fig. 2b). In addition, the identified DEPs had high peptide coverage, of which 80 and 54\% showed more than 10 and $20 \%$ sequence coverage, respectively (Fig. 2c). About $74 \%$ of the identified DEPs had three or more peptides (Fig. 2d).

\section{Subcellular localization and canonical pathways of identified DEPs}

To elucidate the functional characteristics of DEPs in the hypothalamus under HS, the DEPs of the hypothalamic tissues were analyzed based on the basic biological functions, clustering of molecular functions, and cell locations of proteins in the UniProtKB/Swiss-Prot,

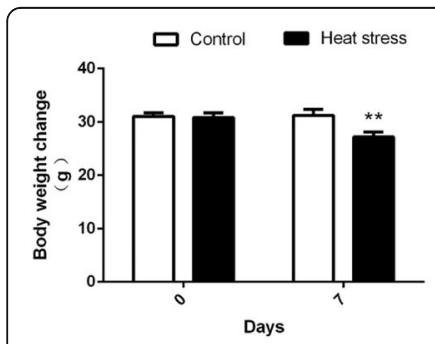

A

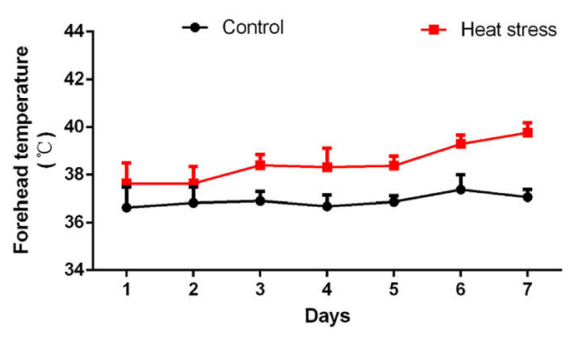

B

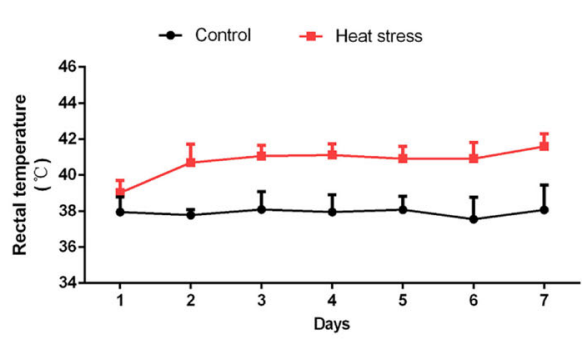

C

Fig. 1 Clinical changes caused by heat stress. (a) Changes in pig body weight, (b) forehead temperature, and (c) rectal temperature, under heat stress 


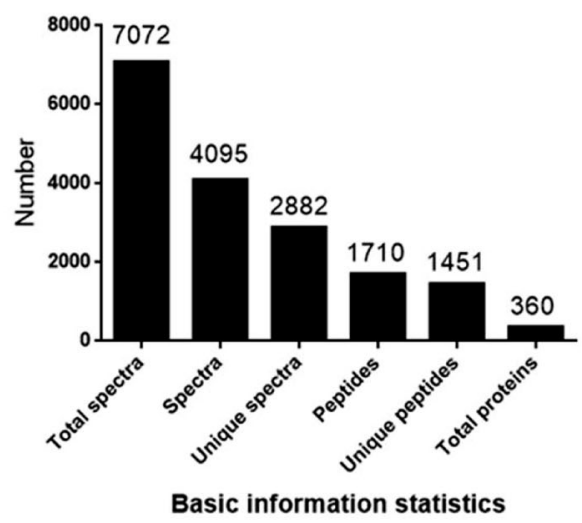

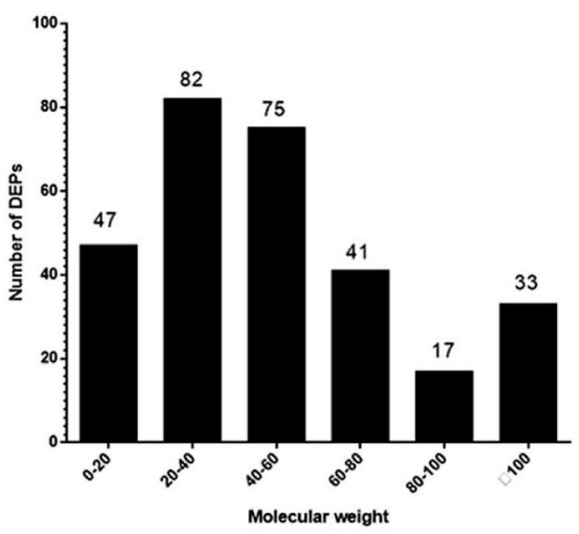

B
A

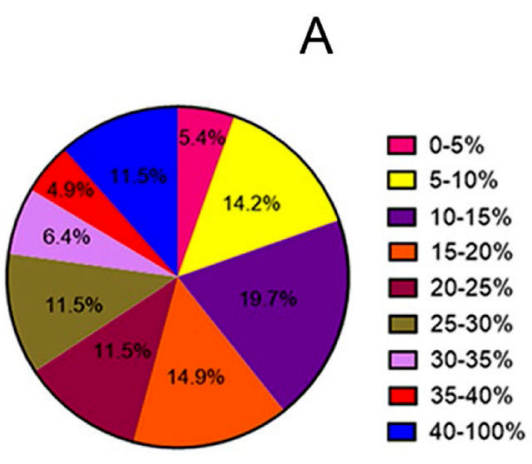

C

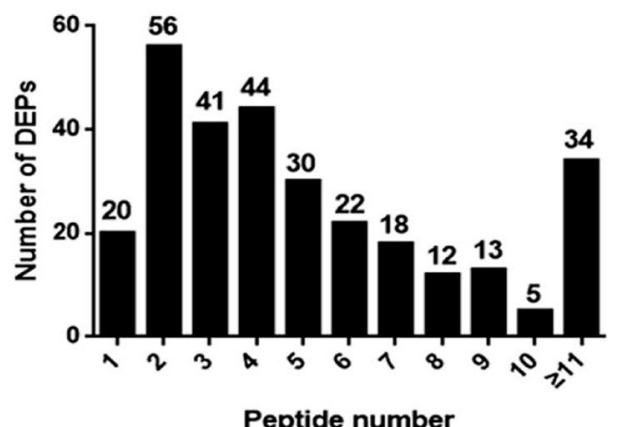

Peptide number

Fig. 2 Protein identification in the hypothalamus of heat-stressed (HS) and control pigs. (a) Numbers of proteins identified, (b) distribution of the DEPs among molecular weight $(\mathrm{kD})$ classes, (c) coverage of DEPs by the identified peptides, and (d) distribution of DEPs containing different numbers of identified peptides

TrEMBL, and Gene Ontology databases. The DEPs identified from hypothalamic tissues are altered by heat stress and are located in different subcellular areas, mainly in cytoplasmic vesicles (14.9\%), cytoskeleton (19.3\%) and non-membrane border organelles (24.4\%) (Fig. 3a).

To better understand these DEPs, further analysis was undertaken using the Ingenuity Pathway Analysis (IPA) tool. Canonical pathways were examined first; the top 30 pathways are shown in Fig. 3b, including pathways related to inflammation and immunity, such as Huntington's disease signaling, clathrin-mediated endocytosis signaling, and Liver $\mathrm{X}$ receptor/Retinoic $\mathrm{X}$ receptor activation (Fig. 3b).

\section{Functional characteristics and bioinformatics analysis of DEPs}

Compared with the human genome database, annotation in the pig genome database is relatively scarce, and many protein features are not identified or classified. The differential proteins identified in our study were converted to the human protein gene bank identification (gi) number. The gi numbers and regulatory levels of these proteins were entered into the IPA software, and based on the database, protein-protein interaction signal pathways were constructed. The proteins identified by iTRAQ in the hypothalamus were clustered according to different functions; four statistically significant functional groups were found, namely, diseases and disorders, molecular and cellular functions, physiological and phylogenetic functions, and toxicological functions (Fig. 4).

The DEPs identified in the hypothalamus of pigs under HS were consistent and corresponded to 23 diseases and disorders including proteins that are related to neurological diseases, psychological disorders, skeletal and muscular disorders, hereditary disorders, metabolic diseases, dermatological diseases and conditions, hematological diseases, immunological diseases, and inflammatory diseases, among others (Fig. 4a). The DEPs could also be assigned to 27 molecular and cellular functions groups, including cell death and survival, cell assembly and organization, cell function and maintenance, 
Table 1 The differentially expressed proteins from hypothalamus in pigs under HS

\begin{tabular}{|c|c|c|c|c|}
\hline Protein name & $\begin{array}{l}\text { Accession } \\
\text { number }\end{array}$ & Peptides & $\begin{array}{l}\text { Ratio (Heat } \\
\text { stress/Control) }\end{array}$ & Functions \\
\hline \multicolumn{5}{|l|}{ Down-regulated in Hypothalamus } \\
\hline Heat shock $70 \mathrm{kDa}$ protein $12 \mathrm{~A}$ & gi|350,593,095 & 7 & 0.439 & ATP binding \\
\hline $\begin{array}{l}\text { Similar to V-type proton ATPase } \\
\text { subunit E } 1 \text { isoform } 2\end{array}$ & gi|350,584,473 & 6 & 0.513 & $\begin{array}{l}\text { hydrogen-exporting ATPase activity, } \\
\text { phosphorylative mechanism }\end{array}$ \\
\hline HPCA & gi|115,394,790 & 7 & 0.151 & actin binding and calcium ion binding \\
\hline Heat shock $90 \mathrm{kD}$ protein 1 , beta & gi|346,986,428 & 15 & 0.666 & GTP, CTP binding and UTP binding, chaperones \\
\hline $\begin{array}{l}\text { Similar to protein kinase } C \text { and casein kinase } \\
\text { substrate in neurons protein } 1 \text {-like }\end{array}$ & gi|335,292,069 & 7 & 0.179 & cytoskeletal protein binding \\
\hline $\begin{array}{l}\text { Tubulin polymerization promoting protein } \\
\text { p25 alpha }\end{array}$ & gi|170,178,280 & 7 & 0.225 & microtubule binding and calcium ion binding \\
\hline Similar to annexin A6-like & gi|350,594,505 & 10 & 0.611 & calcium ion binding \\
\hline Similar to tubulin alpha-4A chain & gi|335,303,414 & 18 & 0.161 & protein binding and GTP binding \\
\hline $\mathrm{Na}+/ \mathrm{K}+$ transporting alpha 3 polypeptide & gi|283,443,672 & 25 & 0.282 & $\begin{array}{l}\text { metal ion binding and sodium: potassium- } \\
\text { exchanging ATPase activity }\end{array}$ \\
\hline $\begin{array}{l}\text { Similar to pyruvate kinase isozymes M1/M2 } \\
\text { isoform } 1\end{array}$ & gi|194,038,728 & 17 & 0.4 & pyruvate kinase activity \\
\hline $\begin{array}{l}\text { Similar to guanine nucleotide-binding protein } \\
\mathrm{G}(\mathrm{I}) / \mathrm{G}(\mathrm{S}) / \mathrm{G}(\mathrm{T}) \text { subunit beta-2-like isoform } 2\end{array}$ & gi|311,251,041 & 5 & 0.474 & signal transducer activity \\
\hline $\begin{array}{l}\text { Similar to erythrocyte membrane protein } \\
\text { band } 4.1 \text {-like } 1 \text { isoform } 1\end{array}$ & gi|335,304,751 & 9 & 0.601 & actin binding and structural molecule activity \\
\hline Tubulin beta-2B chain & gi|343,478,189 & 16 & 0.154 & structural molecule activity \\
\hline Clathrin heavy chain & gi|224,492,556 & 38 & 0.362 & ankyrin binding and structural molecule activity \\
\hline Similar to contactin-1-like isoform 2 & gi|350,584,500 & 12 & 0.343 & glycoprotein binding and carbohydrate binding \\
\hline hexokinase 1 & gi|342,187,282 & 15 & 0.637 & hexokinase activity \\
\hline Similar to synaptic vesicle glycoprotein $2 \mathrm{~A}$ & gi|194,036,298 & 6 & 0.325 & Receptor and transmembrane transporter activity \\
\hline Galectin-1 & gi| $47,716,872$ & 7 & 0.431 & signal transducer activity and laminin binding \\
\hline Synapsin lb & gi|212,525,788 & 13 & 0.205 & ATP binding and actin binding \\
\hline Similar to tubulin alpha-1D chain & gi|194,043,861 & 17 & 0.121 & GTP binding and protein heterodimerization activity \\
\hline \multicolumn{5}{|l|}{ Up-regulated protein in hypothalamus } \\
\hline Annexin A2 & gi| $52,631,987$ & 14 & 2.322 & phosphatidylinositol-4,5-bisphosphate binding \\
\hline Hsp27 & gi| $55,668,280$ & 6 & 2.771 & $\begin{array}{l}\text { protein kinase } C \text { binding and protein } \\
\text { kinase } C \text { inhibitor activity }\end{array}$ \\
\hline Similar to annexin A11 & gi|194,042,189 & 6 & 2.757 & serine-type endopeptidase inhibitor activity \\
\hline Similar to prohibitin & gi|3a50590415 & 6 & 1.519 & $\begin{array}{l}\text { sequence-specific DNA binding RNA } \\
\text { polymerase II transcription factor activity }\end{array}$ \\
\hline $\begin{array}{l}\text { Similar to glyoxalase domain-containing } \\
\text { protein 4-like }\end{array}$ & gi|335,298,275 & 7 & 1.616 & Amino acid transport and metabolism \\
\hline Stress-70 protein, mitochondrial & gi|311,250,237 & 16 & 2.105 & $\begin{array}{l}\text { ATP binding and unfolded protein binding, } \\
\text { testosterone } 17 \text {-beta-dehydrogenase (NADP+) }\end{array}$ \\
\hline Similar to protein disulfide-isomerase A4-like & gi|311,264,773 & 11 & 1.889 & electron carrier activity and protein binding \\
\hline long-chain 3-ketoacyl-CoA thiolase & gi|6,165,556 & 7 & 3.162 & $\begin{array}{l}\text { NAD binding and long-chain- enoyl-CoA } \\
\text { hydratase activity }\end{array}$ \\
\hline Similar to ezrin & gi|350,578,005 & 9 & 4.869 & $\begin{array}{l}\text { cell adhesion molecule binding and actin } \\
\text { filament binding }\end{array}$ \\
\hline Gastrin-binding protein & gi|433,066 & 9 & 2.614 & acetyl-CoA C-acetyltransferase activity \\
\hline Ppk 98; a protein kinase & gi|431,944 & 20 & 1.783 & virion and calcium ion binding \\
\hline 78 kDa glucose-regulated protein & gi|350,579,657 & 22 & 1.634 & chaperone binding and unfolded protein binding \\
\hline Heat shock 10kD protein & gi|30,525,868 & 7 & 10.249 & chaperone binding \\
\hline
\end{tabular}


Table 1 The differentially expressed proteins from hypothalamus in pigs under HS (Continued)

\begin{tabular}{lllll}
\hline Protein name & $\begin{array}{l}\text { Accession } \\
\text { number }\end{array}$ & Peptides & $\begin{array}{l}\text { Ratio (Heat } \\
\text { stress/Control) }\end{array}$ & Functions \\
\hline Similar to caldesmon & gi|311,275,365 & 5 & 2.353 & Calmodulin, actin and myosin binding \\
Similar to annexin A5 & gi|335,293,906 & 12 & 2.117 & calcium ion binding; binding, bridging \\
Similar to annexin A11 & gi|194,042,189 & 6 & 2.757 & serine-type endopeptidase inhibitor activity \\
Similar to selenium-binding protein 1 & gi|194,036,227 & 20 & 2.677 & selenium and protein binding \\
$\begin{array}{l}\text { Non-selenium glutathione phospholipid } \\
\text { hydroperoxide peroxidase (PHGX) }\end{array}$ & gi|6,689,393 & 7 & 2.148 & glutathione peroxidase activity \\
Similar to serpin A3-8 & gi|350,587,171 & 10 & 4.428 & serine-type endopeptidase inhibitor activity \\
Glucosidase 2 subunit beta precursor & gi|347,446,687 & 6 & 1.733 & phosphatidylinositol binding \\
\hline
\end{tabular}

molecular transport, free radical scavenging, cell morphology, small molecule biochemistry, nucleic acid metabolism, lipid metabolism, and cellular development (Fig. 4b); 16 physiological system development and functions groups, including nervous system development and function, tissue morphology, organ morphology, organismal development, tissue development, behavior, organismal survival, embryonic development, organismal function, hematological system development and function, immune cell trafficking, and organ development (Fig. 4c); and 12 toxicity functions groups, namely, liver hyperplasia/hyper-proliferation, renal damage, renal tubule injury, cardiac necrosis/cell death, kidney failure, cardiac arrhythmia, cardiac damage, cardiac inflammation, renal dilation, cardiac dysfunction, liver fibrosis (Fig. 4d).

Among the DEPs identified in the hypothalamus, 13 functional networks were constructed (Fig. 5). The four networks of interest correspond to (1) Cell assembly and tissue, neural development and function, intercellular signal and interaction (Fig. 5a); (2) Nucleic acid metabolism, small molecular biochemistry, and cell morphology (Fig. 5b); (3) Cell assembly and tissue, cell function and maintenance, and neuropathic disease (Fig. 5c); (4) Free radical scavenging, small molecule biochemistry, and cancer (Fig. 5d). Proteins that are present in these pathways and identified as up-regulated DEPs in our analysis are depicted in shades of red and those identified as down-regulated are shown in green. Proteins in the network, but not identified as DEPs in our study, are depicted in white.

\section{Validation of protein identification and quantification}

Histone $\mathrm{H} 2 \mathrm{~A}$ is a type of innate immune molecule discovered in recent years that plays a key role in the phagocytosis of neutrophils and in the clearance of pathogenic microorganisms. To verify the reliability of DEPs identified by iTRAQ, the hypothalamus of pigs on day 7 of HS was used to detect the expression of Histone $\mathrm{H} 2 \mathrm{~A}$ by western blotting. As shown in Fig. 6 (The complete picture was shown in additional Fig. 1), compared with the control group, the expression level of Histone $\mathrm{H} 2 \mathrm{~A}$ in the HS group was significantly upregulated $(p<0.01)$, which was in agreement with the results of the iTRAQ analysis.

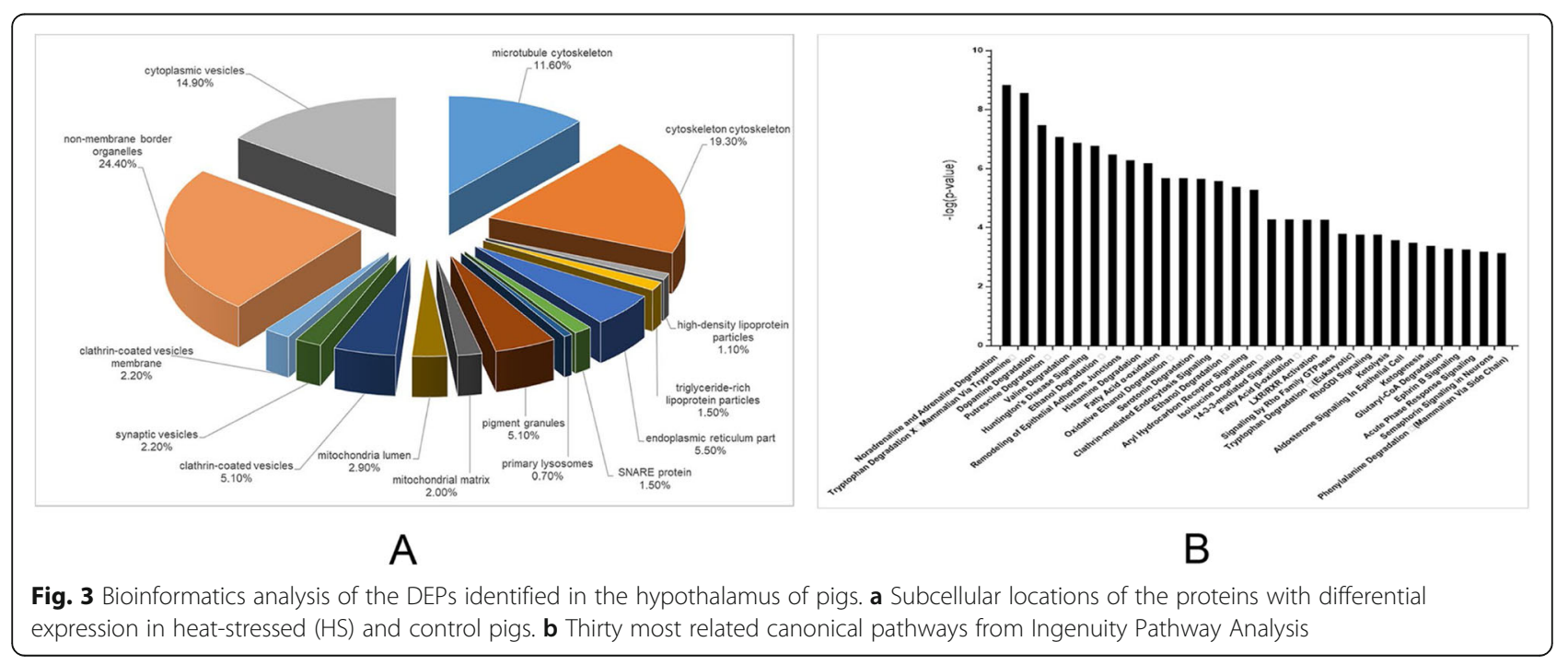




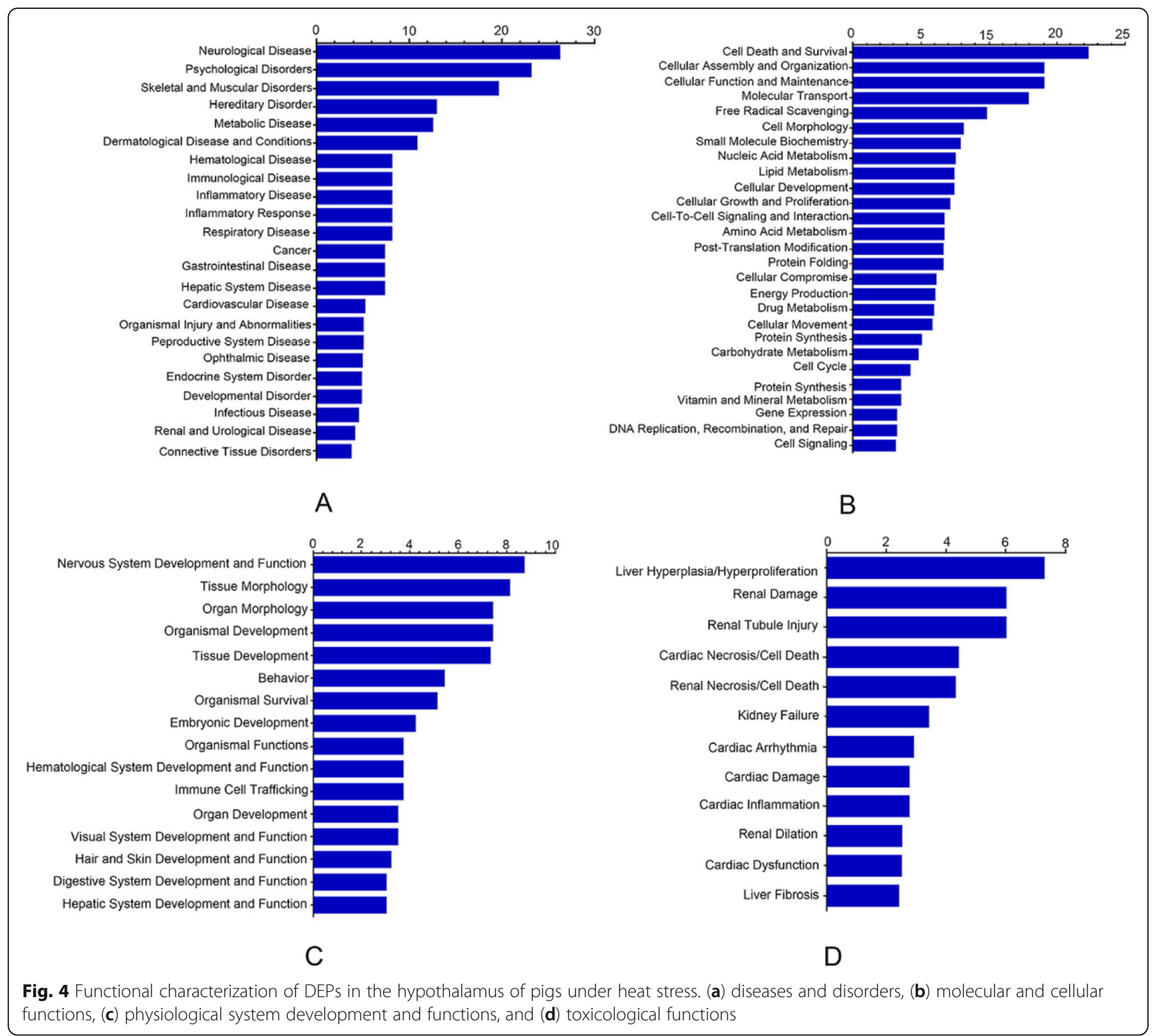

\section{Discussion}

Under stress conditions, endocrine factors such as glucocorticoids and catecholamines can cause immune cell apoptosis, lymphocyte proliferation damage and dendritic cell dysfunction [21, 22], thereby inducing immunosuppression in animals. The body's stress system consists of the hypothalamic-pituitary-adrenal axis, the sympathetic nervous system, and adrenal medulla. The hypothalamus is a vital subcortical center and plays a crucial role in maintaining homeostasis in the body, such as the body's temperature regulation, the balance of water and salt, blood pressure stability, reproductive function integration and regulation of a variety of stress responses. It is important to elucidate the changes in the proteomic of the hypothalamus of heat stressed pigs, as this will facilitate the understanding of the mechanism of immunosuppression in the host. In this study, we identified 295 DEPs in the hypothalamus of heat stressed pigs using iTRAQ technology. The DEPs were mainly distributed in cytoplasmic vesicles, cytoskeleton and non-membrane border organelles, and caused cell death, and immunological and inflammatory diseases. This laid the foundation for systematically revealing the regulatory mechanism of stress-induced immunosuppression.

NADH (Nicotinamide adenine dinucleotide) reacts with free radicals to inhibit lipid peroxidation and protect mitochondrial membranes and mitochondrial function. Studies have found that NADH can reduce the oxidative stress of cells caused by various factors such as radiation, drugs, toxic substances, strenuous exercise, ischemia, etc., thereby protecting vascular endothelial cells, liver cells, cardiomyocytes, fibroblasts, and neurons 


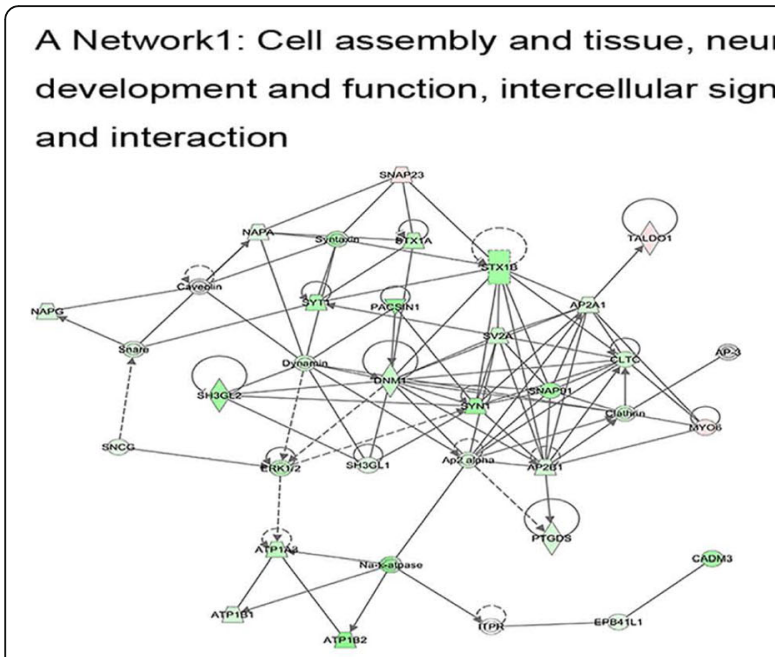

C Network3: Cell assembly and tissue, cell function and maintenance and neuropathic disease

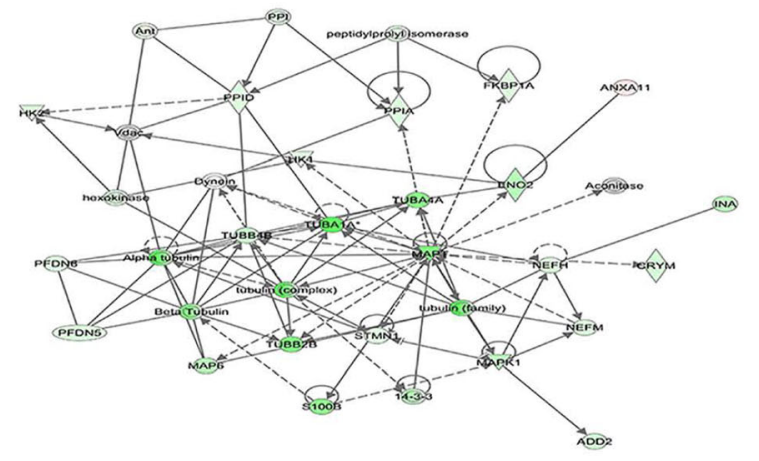

B Network2: Nucleic acid metabolism, small molecular biochemistry and cell morphology

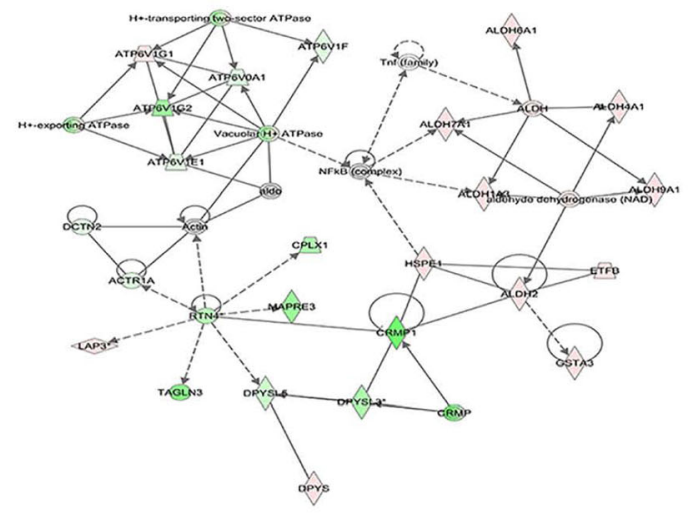

D Network 4: Free radical scavenging, small molecule biochemistry and cancer

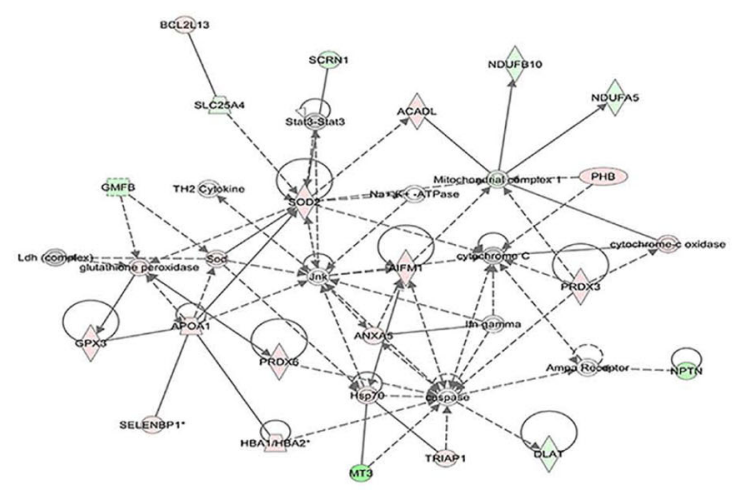

Fig. 5 Ingenuity Pathway Analysis of differentially expressed proteins in the hypothalamus of pigs under heat stress. Red is up-regulated, green is down-regulated, and white is a protein that is involved in pathway regulation but not identified in this study. A darker color indicates a greater change in the expression level of the protein. Different shapes represent different molecular types (e.g., protein families). The lines connecting the molecules represent intermolecular relationships - the dashed lines are indirect effects and the solid lines are direct effects. The arrows represent specific molecular relationships and directions of action

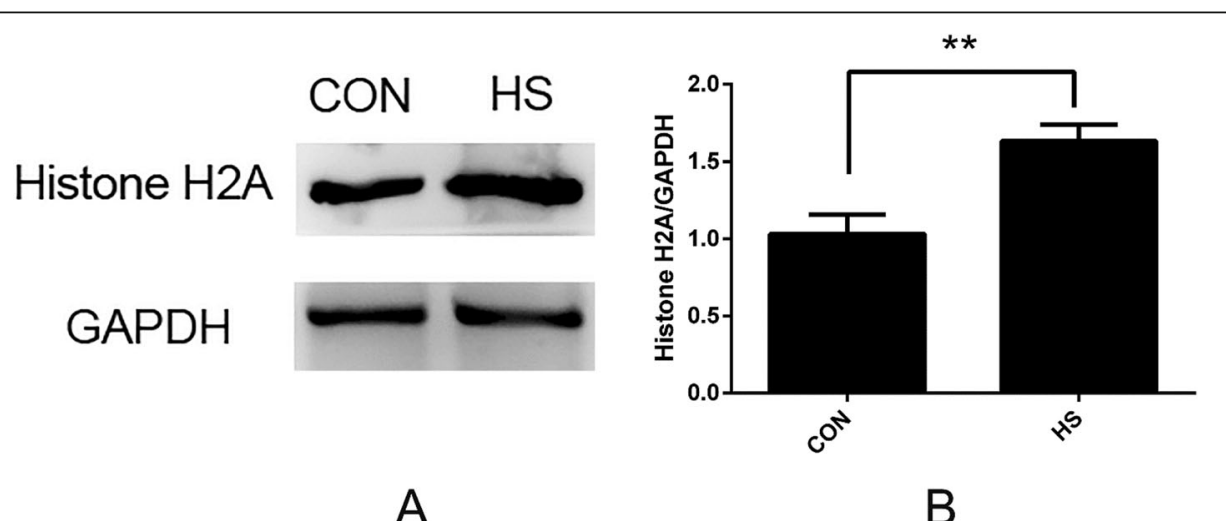

Fig. 6 Western blotting identification of DEPs. a Expression of Histone $\mathrm{H} 2 \mathrm{~A}$ in the hypothalamus of pigs at day 7 of heat stress. Con = control pigs; $\mathrm{HS}=$ heat-stressed pigs. $\mathbf{b}$ Expression of Histone H2A was significantly increased in the HS group compared with the control group 
[23]. Research by He et al. showed that iTRAQ technology identified 212 different proteins in duck meat under heat stress conditions, of which $84 \%$ of down-regulated proteins involved enzymes that regulated the redox reaction process, such as COXs, NADH metabolism, and ATP synthesis/binding related enzymes [24]. The 147 down-regulated proteins in the pig hypothalamus identified in this study include the NADH protein, so it can be concluded that the heat-stressed mitochondrial function and energy supply in the pig hypothalamus caused oxidative damage to the cells.

The heat shock protein (HSP) response is a highly conserved cellular response to external stress in all species. HSPs, including heat shock protein 27 (HSP27), take part in antigen presentation, intracellular trafficking, apoptosis, and act as molecular chaperones by assisting nascent polypeptides in assuming their proper conformations [25]. HSP27 is a multidimensional protein that acts as a protein chaperone and an antioxidant, and plays a role in the inhibition of apoptosis and actin cytoskeletal remodeling [26]. In this study, HSP27 was up-regulated in pig hypothalamus under HS (Table 1), further indicating the role of HSP27 in hypothalamic injury and highlighting its relevance to inflammatory responses.

Histone H2A plays a role in many cell activities such as gene silencing, cell cycle regulation, fatty acid metabolism and apoptosis [27]. Sandra found that Histone H2A was significantly up-regulated in Bacille CalmetteGuerin (BCG)-inoculated mice, indicating that Histone H2A plays a crucial role in inflammation [28]. Nakata found that heat shock could significantly increase the expression of Histone H2A in Hela cells [29]. In this study, up-regulated Histone H2A was found in DEPs of heatstressed pigs. However, Duff's research on bovine respiratory disease found that Histone $\mathrm{H} 2 \mathrm{~A}$ was downregulated in immunosuppressed bovine neutrophils [12]. Hence, in HS, whether the change of $\mathrm{H} 2 \mathrm{~A}$ is related to immunosuppression requires further study. DEPs, along with 13 proteins including Annexin A2 and 17 $\beta$-HSD, proteins were down-regulated in the hypothalamus of heatstroke rats [30], and a majority of these proteins was also found in the hypothalamus of HS pigs. These proteins play a key role in cell migration, free radical scavenging, maintenance of cytoskeleton, organ morphology, and apoptosis.

Das found that heat stress induces Huntington's disease in mice, and HYPK (Huntingtin Yeast Partner K) could alleviate huntington's reaction by suppressing the heat shock response [31]. Clathrin-mediated endocytosis is a type of receptor-mediated phagocytosis that delivers foreign substances from the cell membrane to the endosome, and is used by many viruses-for example, influenza virus [32], hepatitis $C$ virus [33], and Bovine viral diarrhea virus [34] - to complete the cell invasion process. Fujita et al. found that HSP27 phosphorylation could maintain actin stability, thereby stabilizing the cytoskeleton and inhibiting apoptosis to some extent [35]. In this study, functional characterization of DEPs showed that Huntington's disease signaling and clathrinmediated endocytosis signaling may play a role in HS induced physiological disorder in the host. The proportion of DEPs affected by heat stress in cytoskeleton was 19.3\%; HSP27 also showed a downward trend in the hypothalamus, suggesting that heat stress affected the function and maintenance of cells, and induced neurological diseases.

Overall, the IPA showed that these DEPs take part in cell death and survival, cellular assembly and organization, cellular function and maintenance, and are significantly correlated to neurological diseases, metabolic diseases, immunological diseases, inflammatory diseases, and inflammatory responses. These changes may affect the normal functioning of the hypothalamus and result in the faulty regulation of physiology and immune function of the host. Consequently, a decrease in clinical performance, including decrease in body weight, feed consumption, and immunosuppression, may appear in heat stressed pigs.

\section{Conclusion}

In this study, heat stress significantly increased the body temperature and reduced daily gain in pigs. Furthermore, we identified 295 differentially expressed proteins, 147 of which were down-regulated and 148 up-regulated in the hypothalamus of heat stressed pigs. The IPA showed that these DEPs took part in cell death and survival, cellular assembly and organization, cellular function and maintenance, and were related to neurological diseases, metabolic diseases, immunological diseases, inflammatory diseases, and inflammatory responses. The negative effect on hypothalamus function may impair the physical and immune function of the host, resulting in the decrease of growth performance and immunosuppression in heat stressed pigs.

\section{Methods}

Pig feeding and experimentation were carried out in accordance with the National Institutes of Health $(\mathrm{NIH})$ guidelines for the care and use of laboratory animals. Pigs were raised and studied according to the guidelines of the National Institutes of Health (NIH) on raising and using experimental animals. All projects have been approved by the Animal Care and Use Committee of Guangdong Ocean University, China.

\section{Experimental animals and groups}

The castrated Bama miniature pigs were purchased from the Bama mini-pig farm in Bama Miniature Pigs 
Breeding-farm in Guangxi Zhuang Autonomous Region, China, about 3 months, and weighed $15 \pm 1 \mathrm{~kg}$. They were randomly divided into control group $(n=5)$ and heat stress group $(n=5)$ according to one-way ANOVA. The air temperature of the control pigs was $28 \pm 3^{\circ} \mathrm{C}$, while the temperature of the HS group was maintained at $35 \pm 1{ }^{\circ} \mathrm{C}$. The pigs in the control group and the heat stress group were kept separately. The relative humidity for both groups was $80-90 \%$. All pigs had free access to water. The basic diet (see the digestible energy Table 2) was based on the recommended nutritional composition of the pig breed. Pigs were fed twice a day, once in the morning and once in the evening.

\section{Hypothalamus collection}

Pigs were euthanized by a head-only electric stun tong apparatus on the 7th day under HS, followed by manual exsanguination. Immediately after slaughter, the hypothalamus tissue was removed. Subsequently, the tissue was washed with PBS (phosphate buffer saline) to remove any blood and contaminants on the surface of the tissue. The hypothalamic tissue was placed into sterile tubes and snap frozen in liquid nitrogen. In the laboratory, the frozen specimens were stored at $-80^{\circ} \mathrm{C}$ until biochemical and molecular analysis.

\section{Protein extraction and quantification, iTRAQ labeling, and} strong Cation exchange (SCX) fractionation

Frozen hypothalamus tissue from control and heat stress were exposed to liquid nitrogen and were ground into fine powder using a mortar. The powder $(\sim 100 \mathrm{mg}$ per pig) was transferred to sterile tubes with $1 \mathrm{~mL}$ of lysis buffer (pH 8.5; containing $7 \mathrm{~m}$ urea, $2 \mathrm{~m}$ thiourea, $4 \%$ CHAPS, $40 \mathrm{~mm}$ Tris- $\mathrm{HCl}, 10 \mathrm{~mm}$ dithiothreitol) for 5 min. Then, the tissue was homogenized with an Ultrasonic Cell Disruptor (VCX130, USA) at 20\% power output for $10 \mathrm{~min}$ with 2/4-s on/off cycles. Following this, the digest was centrifuged at $25,000 \times g$ for $30 \mathrm{~min}$ at $4{ }^{\circ} \mathrm{C}$, and the supernatant was stored at $-80^{\circ} \mathrm{C}$ for further analysis.The protein concentration in the supernatant was determined using the 2-D Quant Kit (Thermo Fisher Scientific, MA, USA). Protein $(100 \mu \mathrm{g})$ from PAMs was precipitated with acetone overnight at $-20^{\circ} \mathrm{C}$ and dissolved using the iTRAQ dissolution buffer. After reduction and alkylation as described in the iTRAQ protocol (Applied Biosystems), protein solutions were digested overnight at $37^{\circ} \mathrm{C}$ with sequence grade modified trypsin (Promega) and then labeled with the iTRAQ tags as described in the iTRAQ protocol. Subsequently, labeled peptides were combined and fractionated by cation exchange (SCX) chromatography [38] and desalted on C18 Cartridges (66872-U; Sigma, St. Louis, MO, USA). The dried peptide mixture was reconstituted and acidified with $2 \mathrm{~mL}$ of buffer $\mathrm{A}\left(10 \mathrm{mM} \mathrm{KH}_{2} \mathrm{PO}_{4}\right.$ in $25 \%$ of CAN; pH 3.0) and loaded onto a polysulphoethyl $4.6 \times 100 \mathrm{~mm}$ column $(5 \mu \mathrm{m}, 200 \AA$, PolyLC Inc., Maryland, USA). The peptides were eluted at a flow rate of 1 $\mathrm{mL} / \mathrm{min}$ with a gradient of $0-5 \%$ buffer B $(2 \mathrm{~m} \mathrm{KCl}, 10$ $\mathrm{mm} \mathrm{KH} 2 \mathrm{PO} 4$ in $25 \%$ of acetonitrile; $\mathrm{pH} 2.7$ ) for $5 \mathrm{~min}$, 5-10\% buffer B for 10-15 min, 10-30\% buffer B for 25$35 \mathrm{~min}$, and $30-50 \%$ buffer $B$ for $35-50 \mathrm{~min}$. The elution was monitored at $\mathrm{A}_{214}$, and fractions were collected each minute. The collected fractions (about 30 fractions) were finally combined into 10 pools and desalted on C18 Cartridges (Empore ${ }^{\mathrm{Tx}}$ SPE Cartridges C18 (standard density), $7 \mathrm{~mm}$ bed I.D., $3 \mathrm{ml}$ volume, Sigma). Each fraction was concentrated by vacuum centrifugation and reconstituted in $40 \mu \mathrm{L}$ of $0.1 \%(\mathrm{v} / \mathrm{v})$ trifluoroacetic acid. All samples were stored at $-80{ }^{\circ} \mathrm{C}$ until nanoLC-MS/MS analysis was conducted.

\section{LC-MS/MS analysis}

Each fraction was injected for nanoLC-MS/MS analysis. The peptide mixture was loaded onto a reverse phase trap column (Thermo Scientific Acclaim PepMap100, $100 \mu \mathrm{m} \times 2 \mathrm{~cm}$, nanoViper C18) connected to the C18reverse phase analytical column (Thermo Scientific Easy Column, $10 \mathrm{~cm}$ long, $75 \mu \mathrm{m}$ inner diameter, $3 \mu \mathrm{m}$ resin) in buffer A ( $0.1 \%$ formic acid) and separated with a linear gradient of buffer B $(84 \%$ acetonitrile and $0.1 \%$

Table 2 The digestible energy of Bama miniature pigs

\begin{tabular}{llll}
\hline Feed ingredients & Ingredients $/ \%$ & Nutrition level & Ingredients \\
\hline Corn & 70 & Digestive energy ${ }^{\odot /\left(\mathrm{MJ} \cdot \mathrm{kg}^{-1}\right)}$ & 14.23 \\
Soybean meal & 10 & $\mathrm{CP} / \%$ & 14.00 \\
Extruded soybean & 5 & $\mathrm{Ca} / \%$ & 0.50 \\
Rapeseed meal & 5 & $\mathrm{P} / \%$ & 0.43 \\
Soybean oil & 4.8 & Lysine/\% & 0.88 \\
Limestone $^{(1.2}$ & 4 & & \\
Premix $^{(}$ & 4 & & \\
\hline
\end{tabular}

(1)The premix is provided for each kilogram of full price material: Vitamin A 18000 IU, Vitamin D 34000 IU, Vitamin E $100 \mathrm{mg}$, Vitamin B2 $10 \mathrm{mg}$, Vitamin B1 $4 \mathrm{mg}$, Vitamin B12 $40 \mathrm{mg}$, biotin $200 \mathrm{mg}$, pantothenic acid $20 \mathrm{mg}$, niacin $15 \mathrm{mg}$, iron $100 \mathrm{mg}$, copper $30 \mathrm{mg}$, zinc $110 \mathrm{mg}$, manganese $20 \mathrm{mg}$, selenium $0.67 \mathrm{mg}$, cobalt $1 \mathrm{mg}$;

(2) Digestive energy is calculated value, others are measured value 
formic acid) at a flow rate of $300 \mathrm{~nL} / \mathrm{min}$ controlled by IntelliFlow technology. Peptides eluted by high performance liquid chromatography were directly injected into the Q-Exactive mass spectrometer (Thermo Fisher Scientific, MA, USA). Data were acquired in the positive ion mode with a selected mass range of 300-1800 mass/ charge $(\mathrm{m} / \mathrm{z})$ [36]. Q-Exactive survey scans were obtained at $70,000(\mathrm{~m} / \mathrm{z} 200)$ and $17,500(\mathrm{~m} / \mathrm{z} 200)$, with the resolution for higher-energy collisional dissociation spectra and maximum ion injection times fixed at 20 and $60 \mathrm{MS}$, respectively. Dynamic exclusion (40.0 s duration) was used. MS/MS data were collected using the top 10 most abundant precursor ions. The normalized collision energy was $30 \mathrm{eV}$, and the underfill ratio was defined as $0.1 \%$. The instrument was run with the peptide recognition mode enabled.

\section{iTRAQ data analysis}

Protein identifications were performed using the MASCOT engine (version 2.3.02; Matrix Science, London, UK) embedded in Proteome Discoverer 1.4 (Thermo Fisher Scientific). The search parameters were as follows: (1) database, uniprot; (2) taxonomy, Homo sapiens; (3) Enzyme, trypsin; (4) fixed modifications, carbamidomethyl of C, iTRAQ 4plex (N-term), iTRAQ 4plex (K); (5) variable modifications, oxidation of $M$; (6) $\max$ missed cleavages, 2 ; (7) peptide charges state, $+2,+3$, and +4 ; (8) peptide mass tolerance, $20 \mathrm{ppm}$; (9) mass/ mass tolerance, $\pm 0.05 \mathrm{Da}$. Differentially expressed proteins were defined as those that were different by at least 2 -fold between two groups. The data analysis was supported by Wayen Biotechnologies. (Shanghai, China).

\section{Bioinformatics analysis}

Go numbers of all significantly regulated proteins and some unaltered proteins were imported into the Ingenuity Pathway Analysis software (IPA, www.ingenuity.com) for bioinformatics analysis based on published reports and databases such as Gene Ontology, Uniprot, and TrEMBL. The canonical pathways and protein interaction networks of the DEPs were analyzed using the IPA.

\section{Western blotting}

Pig hypothalamus samples from both HS and control groups were homogenized in Radio-Immunoprecipitation Analysis buffer (Thermo Fisher Scientific, MA, USA), followed by ultrasonication on ice. Homogenates were then incubated on ice for $20 \mathrm{~min}$ and centrifuged at 12 , $000 \times g$ for $15 \mathrm{~min}$ at $4{ }^{\circ} \mathrm{C}$. Supernatants were collected and total protein concentration measured using the $\mathrm{BCA}$ assay. Next, protein degeneration was performed at $100^{\circ} \mathrm{C}$ for $10 \mathrm{~min}$. Proteins were separated on SDS-PAGE gels, then transferred to PVDF (polyvinylidene fluoride) membranes and blocked in 5\% non-fat dry milk/TBST solution at $37^{\circ} \mathrm{C}$ room temperature for $2 \mathrm{~h}$. Membranes were incubated overnight at $4{ }^{\circ} \mathrm{C}$ in western blotting diluent containing primary antibodies: histone H2A (1:1000; Abcam, Cambridge, UK), and GAPDH (1:1000; Cell Signaling Technology, America). After washing them four times with TBST, membranes were incubated in blocking solution containing anti-rabbit secondary antibodies (1:1000) at $37^{\circ} \mathrm{C}$ for $1 \mathrm{~h}$. Blots were visualized using an ECL detection system and proteins were quantified using a ChemiDoc XRS+ image analyzer (Bio-Rad, Hercules, CA, USA). Densitometric analysis was used to evaluate the expression levels of target proteins. Ratios of densitometric measurements of target proteins relative to GAPDH were compared between control and HS groups. Three experimental replicates were performed, and independent Student's t-test was used to assess statistical difference.

\section{Statistical analysis}

Statistical analysis was performed using SPSS Statistics 22.0. Analysis of difference in protein expression between the HA group and the CA group were performed using a t-test; $p<0.01$ was set as value to indicate statistical significance.

\section{Supplementary information}

Supplementary information accompanies this paper at https://doi.org/10. 1186/s12917-020-02505-1.

Additional file 1: Supplementary Table 1. The significantly changed protein in hypothalamus of pigs under HS.

Additional file 2: Additional figure 1.

\section{Abbreviations}

17ß-HSD: 17ß-Hydroxysteroid dehydrogenases; ANXA: Annexins; DEPs: Differentially expressed proteins; HS: Heat stress; HSP: Heat shock protein; IPA: Ingenuity pathway analysis; iTRAQ: Isobaric tags for relative and absolute quantification; LC-MS/MS: Mass spectrometry

\section{Acknowledgements}

We acknowledge Prof. Dr. Ju's team at the Stress student laboratory, Department of Veterinary Medicine, Guangdong Ocean University, for their assistance with this work.

\section{Authors' contributions}

TY and YY contributed equally to this work. TY conceived the study, designed the experiments, prepared the samples for mass spectrometry and analyzed the mass spectrometry data, conducted the experimental work, created the figures, and wrote the manuscript. and YY participated in the enrichment analysis, created the pathway figure, and aided in revising the manuscript. $J \mathrm{~L}, \mathrm{BF}, \mathrm{XL}$, and $\mathrm{YP}$ analyzed the mass spectrometry data, participated in the enrichment analysis, and participated in the writing and revision of the manuscript. $R G$ aided in the conceptual framework of the study, and revised the manuscript. ZY, XM, LW and $\mathrm{CH}$ were responsible for animal care. $X J$ provided financial support, designed the experiments, and revised the manuscript. All authors have read and approved the final version of the manuscript.

\section{Funding}

This work was supported by the Project of Enhancing School with Innovation at Guangdong Ocean University (grant number 230419057), National Natural Science Foundation of China (grant nos. 31101862, 31472243) and Shenzhen Projects for Basic Research 
(JCYJ20170306162414058, JCYJ20190813142005766). The funding bodies had no role in the design of the research, the collection, analysis, and interpretation of data, and the writing of the manuscript.

\section{Availability of data and materials}

The datasets used and/or analyzed during the current study are available from the corresponding author upon reasonable request.

\section{Ethics approval and consent to participate}

The protocol was approved by the Committee on the Ethics of Animal Experiments at Guangdong Ocean University (Permit No.: 201-1231). All surgeries were performed under sodium pentobarbital anesthesia, and every effort was made to minimize suffering.

\section{Consent for publication}

Not applicable.

\section{Competing interests}

The authors declare that they have no competing interests.

\section{Author details}

'Department of Veterinary Medicine, Guangdong Ocean University, Zhanjiang 524088, China. ${ }^{2}$ Shenzhen Institute of Guangdong Ocean University, Shenzhen 518018, China. ${ }^{3}$ Department of Animal Science, Guangdong Ocean University, Zhanjiang 524088, China. ${ }^{4}$ Faculty of Agriculture and Life Sciences, Lincoln University, Lincoln 7647, New Zealand.

\section{Received: 26 August 2019 Accepted: 30 July 2020}

Published online: 12 August 2020

\section{References}

1. Seibert J, Abuajamieh M, Sanz MV, Johnson J, Kvidera S, Horst E, Mayorga J, Lei S, Patience J, Ross J, et al. Effects of heat stress and insulin sensitizers on pig adipose tissue. J Anim Sci. 2018;96(2):510-20.

2. Pearce S, Lonergan S, Huff-Lonergan E, Baumgard L, Gabler N. Acute heat stress and reduced nutrient intake Alter intestinal proteomic profile and gene expression in pigs. PLoS One. 2015;10:e143099.

3. Cui Y, Hao Y, Li J, Bao W, Li G, Gao Y, Gu X. Chronic heat stress induces immune response, oxidative stress response, and apoptosis of finishing pig liver: a proteomic approach. Int J Mol Sci. 2016;17:393.

4. Gregory NG. How climatic changes could affect meat quality. Food Res Int 2010;43(7):1866-73.

5. Mills K, Feldpausch J, Duttlinger A, Elefson S, Zuelly S, Radcliffe J, Rambo Z, Richert B. 252 effect of cyclic heat stress and supplemented inorganic and organic zinc source levels on grow-finish pig growth performance and estimated body composition. J Anim Sci. 2018;96:134-5.

6. Bell JA. Selective blockade of spinal reflexes by $\omega$-conotoxin in the isolated spinal cord of the neonatal rat. Neuroscience. 1993;52:711-6.

7. Ju X, Yan-Hong Y, Han-Jin X, Li-Long A, Ying-Mei X, Jiao P, Ming L. Selection of reference genes for gene expression studies in PBMC from Bama miniature pig under heat stress. Vet Immunol Immunop. 2011;144:160-6.

8. Zhao ZQ, Liu JH, Lei H, Duan L, Cao R, Wan Q, Zhao G, Rao ZR. Expression of GFAP in rat hypothalamus after different temperature heat stresses. Acta Anatomica Sinica. 2007;38:525-7.

9. Odeon M, Yamauchi L, Grosman M, Acosta G: Long-term effects of repeated maternal separation and ethanol intake on HPA axis responsiveness in adult rats. Brain Res. 2017;1657:193-201.

10. Sutherland A, Webb S, Rodriguez-Zas S, Salak-Johnson J. Impact of chronic stress and social status on various physiological and performance measures in pigs of different breeds. J Anim Sci. 2006;84:588-96.

11. Kataria N, Kataria AK. Alterations in prolactin and cortisol levels in heat stressed pigs from arid tracts in India. Porcine Res. 2013;3(1):4-8.

12. Duff G, Galyean ML. BOARD-INVITED REVIEW: recent advances in management of highly stressed, newly received feedlot cattle. J Anim Sci. 2007:85:823-40.

13. Xie $X$, Wang $X$, Liu L. ITRAQ technology and its application in proteomics. Chin J Biochem Mol Biol. 2011;27:616-21.

14. Poirrier J, Guillonneau F, Renaut J, Sergeant K, Luxen A, Maquet P, Leprince P. Proteomic changes in rat hippocampus and adrenals following shortterm sleep deprivation. Proteome Sci. 2008;6:14.
15. Ribeiro E. Studying the central control of food intake and obesity in rats. Revista De Nutrio. 2009;22(1):163-71.

16. Sarkar P, Sarkar S, Ramesh V, Kim H, Barnes S, Kulkarni A, Hall J, Wilson B, Thomas R, Pellis N, et al. Proteomic analysis of mouse hypothalamus under simulated microgravity. Neurochem Res. 2008;33:2335-41.

17. Fouillen L, Petruzziello F, Veit J, Bhattacharyya A, Kretz R, Rainer G, Zhang X. Neuropeptide alterations in the tree shrew hypothalamus during volatile anesthesia. J Proteome. 2013;80:311-9.

18. Martyniuk C, Kroll K, Doperalski N, Barber D, Denslow N. Genomic and proteomic responses to environmentally relevant exposures to Dieldrin: indicators of Neurodegeneration? Toxicol Sci. 2010;117:190-9.

19. Garcia-Segura L, Lorenz B, Doncarlos $L$. The role of glia in the hypothalamus: Implications for gonadal steroid feedback and reproductive neuroendocrine output. Reproduction (Cambridge). 2008;135:419-29.

20. Ju X, Xu H, Yong Y, An L, Jiao P, Liao M. Heat stress upregulation of toll-like receptors $2 / 4$ and acute inflammatory cytokines in peripheral blood mononuclear cell (PBMC) of Bama miniature pigs: An in vivo and in vitro study. Animal. 2014;8:1-7.

21. Fontana JM, Bankamp B, Rota PA: Inhibition of interferon induction and signaling by paramyxoviruses. Immunol Rev. 2010, 225(1):46-67.

22. Schneider-Schaulies J, Schneider-Schaulies S. Receptor interactions, tropism, and mechanisms involved in morbiltivirus-induced immunomodulation. Adv Virus Res. 2008;71:173.

23. Burschel S, Decovic DK, Nuber F, Stiller M, Hofmann M, Zupok A, Siemiatkowska B, Gorka M, Leimkühler S, Friedrich T: Iron-sulfur cluster carrier proteins involved in the assembly of Escherichia coli NADH: ubiquinone oxidoreductase (complex I). Mol Microbiol. 2019;111(1):31-45.

24. He J, Xia C, He Y, Pan D, Cao J, Sun Y, Zeng X. Proteomic responses to oxidative damage in meat from ducks exposed to heat stress. Food Chem. 2019;295:129-37.

25. Bradke F, Fawcett J, Spira M. Assembly of a new growth cone after axotomy: the precursor to axon regeneration. Nat Rev Neurosci. 2012;13: 183-93.

26. Vidyasagar A, Wilson N, Djamali A. Heat shock protein 27 (HSP27): biomarker of disease and therapeutic target. Fibrogenesis Tissue Repair. 2012;5:7.

27. Higashi M, Inoue S, Ito T. Core histone H2A ubiquitylation and transcriptional regulation. Exp Cell Res. 2010;316:2707-12

28. Rodriguez-Zas S, Wu C, Southey B, O'Connor J, Nixon S, Garcia R, Zavala C, Lawson M, McCusker R, Romanova E, et al. Disruption of microglia histone acetylation and protein pathways in mice exhibiting inflammationassociated depression-like symptoms. Psychoneuroendocrino. 2018;97:47.

29. Nakata S, Watanabe T, Nakagawa K, Takeda H, Ito A, Fujimuro M. The dynamics of histone H2A ubiquitination in HeLa cells exposed to rapamycin, ethanol, hydroxyurea, ER-stress, hydroxyurea, heat-shock and DNA damage. Biochem Bioph Res Co. 2016;472(1):46-52.

30. Campos Martorell M, Salvador N, Monge M, Canals F, García Bonilla L, Hernández-Guillamon M, Ayuso M, Chacón P, Rosell A, Alcazar A, et al. Brain proteomics identifies possible simvastatin targets in acute phase of stroke in a rat embolic model. J Neurochem. 2014;130(2):301-12.

31. Das S, Bhattacharyya N. Huntingtin interacting protein HYPK is a negative regulator of heat shock response and is downregulated in models of Huntington's disease. Exp Cell Res. 2016;343:107-17.

32. Edinger T, Pohl M, Stertz S. Entry of influenza a virus: host factors and antiviral targets. J Gen Virol. 2014;95:263.

33. Ploss A, Evans M. Hepatitis C virus host cell entry. Curr Opin Virol. 2012;2:14-9.

34. Lecot S, Belouzard S, Dubuisson J, Rouille Y. Bovine viral diarrhea virus entry is dependent on Clathrin-mediated endocytosis. J Virol. 2015;79(16):10826-9.

35. Fujita Y, Ohto E, Katayama E, Atomi Y. B-Crystallin-coated MAP microtubule resists nocodazole and calcium-induced disassembly. J Cell Sci. 2004;117(Pt 9):1719-26.

36. Li JY, Yong YH, Gong DL, Shi L, Wang XM, Gooneratne R, Yadnyavalkya $\mathrm{P}$, Ju $\mathrm{XH}$. Proteomic analysis of the response of porcine adrenal gland to heat stress. Res Vet Sci. 2019;122:102-10.

\section{Publisher's Note}

Springer Nature remains neutral with regard to jurisdictional claims in published maps and institutional affiliations. 